\title{
Challenges to Development Study in A Spatially Changing World Order (Indonesian Case Study)
}

\author{
Bangun Muljo Sukojo \\ Department of Geomatics Engineering, Institut Teknologi Sepuluh Nopember, Surabaya, Indonesia \\ e-mail: bangun_ms@geodesy.its.ac.id
}

\begin{abstract}
International power relations changing and how can global peace and stability be maintained? With some main theories of international relations, shows how the global order is gradually changing and discusses how selected international and regional organizations contribute to the maintenance of global peace and security. Most importantly, It was seeing the confluence of high levels of indebtedness and extremely low interest rates which limits central banks' powers to stimulate the economy, large wealth gaps and political divisions within countries which leads to increased social and political conflicts. The COVID-19 pandemic has caused a historic setback to decades of development progress, and also exposed gaps in regional cooperation. The vertical across shows the number of COVID-19 death per million, as of August 30. The horizontal axis shows the percentage decline of GDP relative to the same quarter in 2019. It is ajusted for inflation This is a moment for reflection for policy makers across Asia and the Pacific and, as COVID-19 reshapes the world, we need to think innovatively on how future regional cooperation could be strengthened and be more agile in addressing the development challenges of our time. Disasters are usually difficult to avoid, but they can actually be mitigated. For a long time, the campaign on disaster awareness has been echoed. The idea of a disaster-aware community needs to be fully animated. The place (spatial) needs to be designed in such a way so that people are aware of the threat of disasters that can come at any time. Here we see an imbalance, on the one hand, humans are now very advanced (advanced) designing and executing many things: how to create connectivity, ease of moving, and speed of communication. However, on the other hand we fail to think about the (Geospatial) places in which humans live their lives.
\end{abstract}

Keywords-COVID-19; Disasters; Geospatial International power.

\section{INTRODUCTION}

$\mathrm{H}$ OW are international power relations changing and how can global peace and stability be maintained? With some main theories of international relations, shows how the global order is gradually changing and discusses how selected international and regional organizations contribute to the maintenance of global peace and security. Most importantly, It was seeing the confluence of high levels of indebtedness and extremely low interest rates which limits central banks' powers to stimulate the economy, large wealth gaps and political divisions within countries which leads to increased social and political conflicts, and a rising world power (China) challenging the overextended existing world power (the US). [1]

The COVID-19 pandemic has caused a historic setback to decades of development progress, and also exposed gaps in regional cooperation. Figure 1 is the graph of economic decline in the second quarter of 2020 versus the rate of confirmed death due to COVID-19. The vertical across shows the number of COVID-19 death per million, as of August 30.

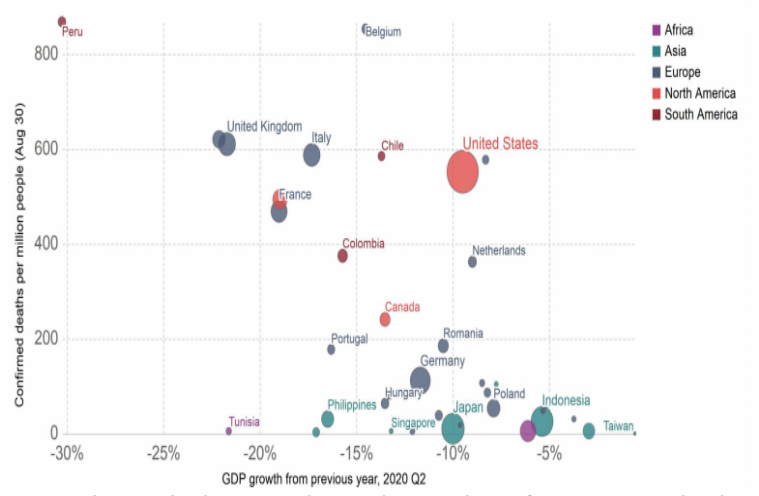

Figure 1. The vertical across shows the number of COVID-19 death per million, as of August 30

The horizontal axis shows the percentage decline of GDP relative to the same quarter in 2019. It is adjusted for inflation.

This is a moment for reflection for policy makers across Asia and the Pacific and, as COVID-19 reshapes the world, we need to think innovatively on how future regional cooperation could be strengthened and be more agile in addressing the development challenges of our time. Disasters are usually difficult to avoid, but they can actually be mitigated. For a long time, the campaign on disaster awareness has been echoed. The idea of a disaster-aware community needs to be fully animated. The place (spatial) needs to be designed in such a way so that people are aware of the threat of disasters that can come at any time.

Here we see an imbalance, on the one hand, humans are now very advanced (advanced) designing and executing many things: how to create connectivity, ease of moving, and speed of communication. However, on the other hand we fail to think about the (Geospatial) places in which humans live their lives.

\section{SPATIAL INFORMATION}

Geospatial information is all types of information that have a location element (geo-reference), both on the surface, inside and above the surface of the Earth. Geospatial element are consist of location, shape, dan attribute. Geospatial Information is linking society, the economy and the environment for achieving Sustainable Development Goals. There are 12 Goals to transform our world such us no poverty, zero hunger, good health, quality education, gender equality, peace, justice, and strong institutions, etc. Based on law no. 4/2011 Republic of Indonesia, Geospatial Information Management in Indonesia divided into 3 main roles including Basic Geospatial Information, Thematic Geospatial 


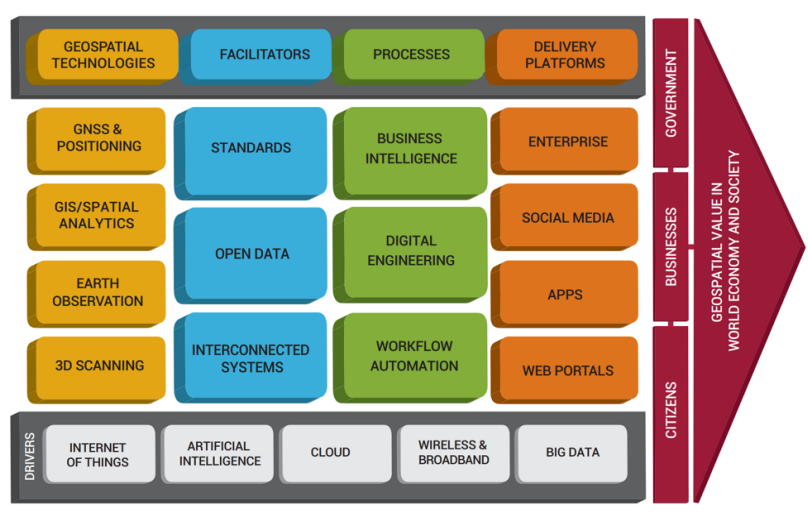

Figure 2. The Process of Geospatial Technology in Digital Transformation Era.

Information, and Geospatial Information Infrastructure. Geospatial Information is compulsory for supporting sustainable development of Indonesia and managing its natural resources. Indonesia has vast territory and abundant land and marine resources which has total $8.300 .000 \mathrm{Km} 2$ area of land and water. Indonesia however is also prone to several natural disasters: earthquakes, tsunami, volcano eruption, flooding, landslides, etc. and Geospatial Information is compulsory for supporting Disaster Risk Reduction Management activities.

Remote Sensing Technology is part of Geospatial Technology. Remote Sensing is defined as the acquisition of information about an object without being in physical contact with it. Information is acquired by detecting and measuring changes that the object imposes on the surrounding field, be it an electromagnetic, acoustic, or potential. This could include an electromagnetic field emitted or reflected by the object, acoustic waves reflected or perturbed by the object, or perturbations of the surrounding gravity or magnetic potential field due to the presence of the object. (Elachi and van Zyl, 2006). Utilize the advancements in digital information era to also improve the performance of Remote Sensing Applications as seen in Figure 2.

\section{INDONESIA ONE MAP POLICY (STATUS AND FUTURE PLAN)}

There are several reason that underlie this policy making including the low quality of spatial based decision making, the overlapping and conflicts in land use and area boundary, and the land use that is not in accordance with the Spatial Plan. Based on law no. 4/2011 Republic of Indonesia, Geospatial Information Management in Indonesia divided into 3 main roles including Basic Geospatial Information, Thematic Geospatial Information, and Geospatial Information Infrastructure. The Basic and infrastructure Geospatial Information are maintained by GIA of Indonesia. However thematic Geospatial Information is created by ministries, agencies, and each local governments. So far, each stakeholder uses different format and standard of thematic and base maps to do activities such as the references and standards are not uniform, map accuracy is still diverse, not

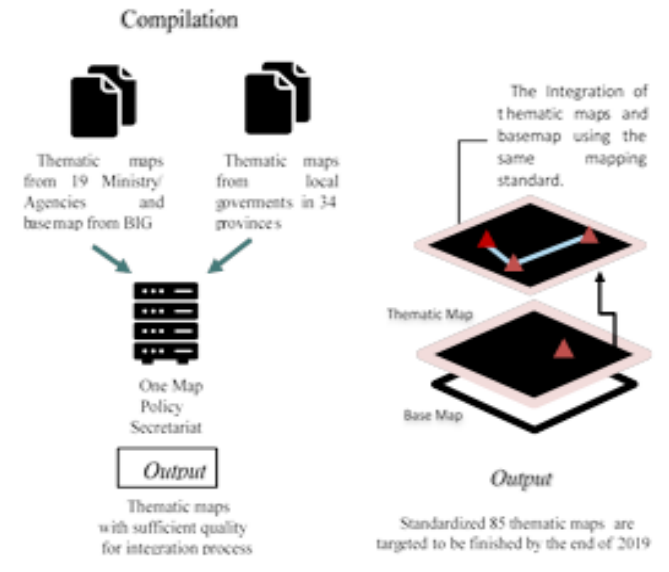

Synchronization

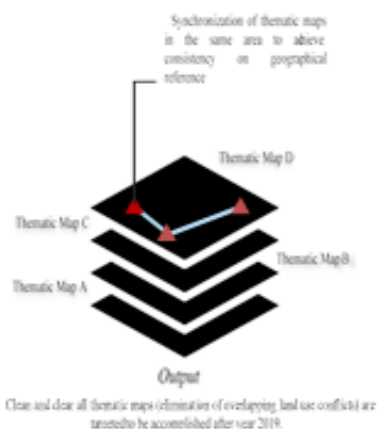

Figure 3. The Process of One Map Policy Main Program.

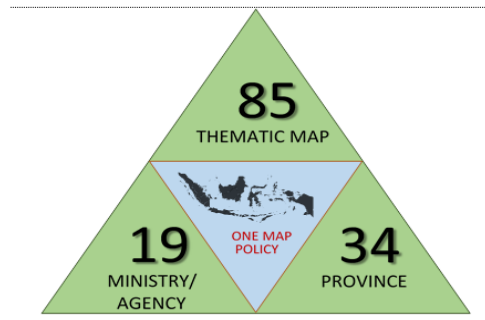

Figure 4. Overview of Indonesia One Map Policy.

always up-to-date, accessibility is still a problem, and the data sharing is often difficult.

Another problem that is often encountered in thematic mapping in local areas are 1) The other Thematic mapping carried out by the central and local governments and nongovernmental institution has not been well coordinated, 2) the number of thematic maps is relatively large and not all of them are clear who their custodian are, 3) the same thematic maps are often published by more than one party without coordination, 4) thematic maps often use different base maps, and 5) thematic maps have not all been stored in a digital database that is easy to access and share quickly. So, one system of accurate and reliable maps as the reference for all stakeholders in formulating development planning is needed.

The One Map Policy is needed for improving the quality of Spatial Planning, National Resources Management, Sustainable Development, Disaster Risk Reduction Management, Policy and Decision Making, and Digital Economy Development. There are four main Program of One Policy Map as seen in Figure 3, including Compilation, Integration, Synchronization, and Data Sharing. In Indonesia 
The $2^{\text {nd }}$ International Conference on Global Development - ICODEV

December $5^{\text {th }}, 2020$, Online Conference

Table 1.

The Status of Network Nodes

\begin{tabular}{ccc}
\hline \hline $\begin{array}{c}\text { Status of Network } \\
\text { Nodes (July 2019) }\end{array}$ & TARGET & CONNECTED \\
\hline Ministry/Agency & 65 & 27 \\
Province & 34 & 34 \\
Regency/City & 518 & 74 \\
University & 34 & 20 \\
\hline \hline
\end{tabular}

there are 19 Ministries/Agencies and 85 Thematic Maps as depicted in Figure 4.

As a follow up to the President's direction to resolve the overlapping problems of land use in all regions of Indonesia, the Secretariat of the OMP team has completed the identification of overlapping land use issues in 6 regions. The Secretariat of the OMP Team has determined the rule base to solve the overlapping problems based on the following basic principles:

\section{1) Legal Legitimacy}

Every mechanism for settlement of overlapping problem should be based on the legitimate legal basis and have a binding force.

\section{2) Respect for Community Rights}

Community rights take precedence above other interests, as long as these rights can be proven physically and administratively.

\section{3) Investment Assurance}

Overlapping problem solving should encourage investment through guaranteeing the rights of legitimate business entities.

\section{4) Safeguarding Of Environmental Sustainability}

The rule base should pay attention to ecosystem preservation and environmental sustainability.

The relative priority scale between the four principles depends on the pattern of problems faced. In each pattern of problems, there is one principle that will become objective function while the other three principles are constraints.

According the Presidential Regulation No. 27 of 2014, which is based on Law No. 4 of 2011, the National Geospatial Information Network (NIGN) functions as a means of sharing and disseminating Geospatial Informatio through Network Nodes. The current status of Network Nodes can be seen in Table 1.

So there are some things that must be considered by GIA including: 1) strengthening NIGN and its Network Nodes, 2) acceleration of village boundary mapping, 3) effective updating of base maps, 4) Acceleration of large-scale base maps.

Presidential Direction in Launching of One Map Policy Geoportal 11 December 2018 consist of:

1) Ministries/Agencies should immediately add more thematic maps needed for completion of overlapping land use issues.

2) Ministries/Agencies and Local Governments should immediately utilize the Map of Indicative Overlapping as a working map for resolving the overlapping land uses.

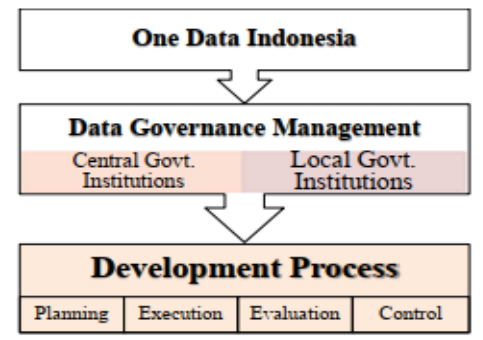

Figure 5. One Data Indonesia Regulation.

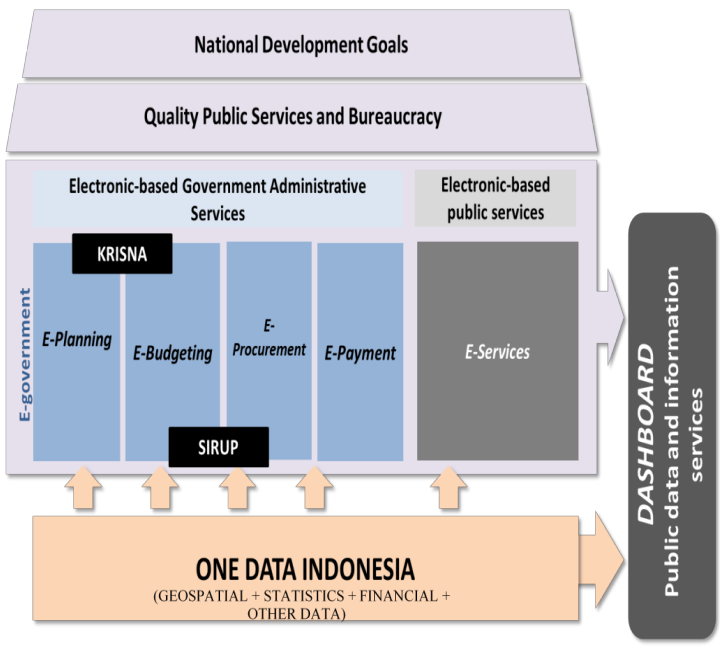

Figure 6. One Map Policy integration with One Data Indonesia.

3) Ministries/Agencies and Local Governments should immediately utilize the One Map Policy product for spatial-based development planning.

4) Ministries/Agencies and Local Governments should collaborate in resolving the overlapping land use issues.

5) Head of local governments should accelerate the establishment of village boundaries, and coordinate its technical mapping with the Geospatial Information Agency (GIA).

The next important task is to integrate the One Map Policy program with the government's new program, namely One Data Indonesia. One Data Indonesia (ODI) is a governance policy of government data to produce data that is accurate, up-to-date, integrated, reliable, and easily accessible and shared between central and local agencies through compliance with Data Standards, Metadata, Data Interoperability, and using Reference Codes and Main Data. (Article 1, Presidential Regulation 39/2019). One Data Indonesia intended to regulate the governance management of data generated by the Central and Local Government Institutions to support planning, execution, evaluation, and control of development (Article 2.1, Presidential Regulation 39/2019) as figured in Figure 5. The integration of OMP and ODI can be seen in Figure 6.

\section{THE ROLE OF HIGHER EDUCATION IN THE 'NEW NORMAL' LIFE}

This new normal life requires people to be able to adapt to new situations and environments. It is said, in a new normal life order, people need to be aware and obey in changing their lifestyle. People must be able to adapt to new situations and 
environments, which require them to strengthen their physical immunity. In addition, people must also be able to adapt to their routines, by reducing physical contact, avoiding crowds, working and studying from home only. In essence, new normal life requires a transformation of behavior, culture, and values which are also eroded in the transformation process.

This is where the role of higher education is urgently needed to provide proper education to the public so that they are able to transform properly in facing Covid-19. The role of the campus is also needed to conduct scientific studies in socio-anthropology or psychology-anthropology, even contextual religions. These concepts can then be simplified so that they are easy to implement in order to reconstruct this phenomenon from a scientific and religious perspective.

Based on the evaluation results of the Ministry of Education and Culture, online learning carried out by lecturers and students runs quite effectively even though changes occur in a relatively short time. As many as $33.51 \%$ of students stated that they were able to understand online learning material, $30.90 \%$ understood the material well, and $5.64 \%$ understood the material very well. The results of the evaluation also stated that as many as $25.34 \%$ of students stated that lecturers were able to deliver course material online, $45.56 \%$ of lecturers delivered course material well, and $15.84 \%$ of lecturers delivered lecture materials very well.

At first everyone was worried whether the tertiary institution was ready, in fact more than $80 \%$ stated that online learning was running quite effectively. In delivering lecture materials, learning materials, as well as assessments as well as student absorption capacity does not decrease. Although there are still obstacles that students encounter while undergoing long-distance education (Pembelajaran Jarak $J a u h /$ PJJ), including an unstable internet network and requires a fairly large internet quota, especially when having to do video conferencing with lecturers.

The important role of tertiary institutions in cooperating with religious / custom / community leaders and in addressing the meaning of new normal life from a cultural (horizontal) and religious (vertical) perspective. In addition, there needs to be a study whether cultural and religious values can adopt this paradigm and how is the model of adaptation? Will it lead to a degradation of faith or vice versa to become stronger and crystallized in a new norm and entity? How does religion translate new normal life in the context of spiritual life that has an impact on others and the surrounding environment?

\section{CONCLUSION}

Currently, it has penetrated into the fields of technology, economy, social and culture, where the demands are increasing and complex, both at the national and international levels, its role can also be active and massive. Our participation, academics and practitioners, is to help the government related to public education, not only to be aware and obedient to technological advances, but also in fields related to national development, to overcome natural and human disasters such as the Covid-19 pandemic. So it is hoped that life with spatial information will emerge better activities in the welfare of society.

\section{RECOMMENDATION}

1. To understand the development of the world and its dynamics, basic and applied knowledge based on spatial information is required.

2. Development of a region, region and country and cannot be separated from public awareness, therefore education and local wisdom is a necessity that must be developed comprehensively.

3. Currently, the academic / tertiary environment should be given a wider role to help government and society at large in a more integrated development.

4. With knowledge based on technical skills and reasoning that is rooted in commendable policies and ethics, it is hoped that a new life will emerge better even though some people's habits have changed.

\section{REFERENCES}

[1] M.O. Hosli, The Changing Global Order, Cham: Springer Nature Switzerland AG. 2020.

[2] Indonesia Geospatial Information Agency, "Introduction: Geospatial Information and Remote Sensing."2020.

[3] Indonesia Geospatial Information Agency, "One Map Policy: Status and Future Plans." 2020.

[4] Indonesia Geospatial Information Agency, "From One Map Policy to One Data Indonesia," 2020.

[5] B. Susantono and C. Y. Park, Future of Regional Cooperation in Asia and The Pacific, Mandaluyong City: Asian Development Bank. 2020.

[6] Koentjaraningrat, Kebudayaan Jawa, Jakarta: PN Balai Pustaka. 1984

[7] M. E. Pangestu, Global growth:anticipating for another economic deceleration?, February 2020.

[8] D. Massey, J.Allen, J. Anderson, Geography Matters! A Reader, Cambridge: Cambridge University Press. 1984.

[9] Direktorat Jendral Pendidikan Tinggi Kemendikbud, "Learning Management System (LMS) Nasional atau Sistem Pembelajaran Daring (SPADA).” 2020. 